\title{
Letters
}

Website: www.bmj.com

Email: letters@bmj.com

\section{Magnetic resonance imaging may be alternative to necropsy}

EDITOR-Certification of the cause of death is a valuable source of information about illness in the community. When a death is unexplained the case is referred to the coroner in England and Wales and the procurator fiscal in Scotland. Although Scottish law does not demand explanation of a nonsuspicious death, in England a cause of death (or mode of death under certain circumstances) must be determined, which often requires a necropsy.

Necropsy is not allowed by many religions, particularly Islam and Judaism, unless demanded by law. Over the past 18 months we have used magnetic resonance imaging to examine 15 patients whose deaths were unexplained. The patients were from areas in the North West region covered by five coroners. Examination of the brain, thorax, and upper abdomen showed that 10 of the patients had disease that was so severe that, had the patients been alive, they would have been at risk of death. In these cases the coroners accepted the magnetic resonance diagnoses as the cause of death. In the other five cases disease was found but was not deemed to be sufficiently severe to be the definite cause of death. As there was uncertainty about the cause a necropsy was done. In four of the five cases necropsy con-

\footnotetext{
Advice to authors

We prefer to receive all responses electronically, sent either directly to our website or to the editorial office as email or on a disk. Processing your letter will be delayed unless it arrives in an electronic form.

We are now posting all direct submissions to our website within 72 hours of receipt and our intention is to post all other electronic submissions there as well. All responses will be eligible for publication in the paper journal.

Responses should be under 400 words and relate to articles published in the preceding month. They should include $\leqslant 5$ references, in the Vancouver style, including one to the BMJ article to which they relate. We welcome illustrations.

Please supply each author's current appointment and full address, and a phone or fax number or email address for the corresponding author. We ask authors to declare any competing interest.

Letters will be edited and may be shortened.

www.bmj.com

letters@bmj.com
}

firmed that the disease shown by magnetic resonance imaging was the cause of death.

Necropsy will always be the standard for determining cause of death, particularly as magnetic resonance imaging cannot show small vessel coronary artery disease. However, for patients whose religious beliefs make necropsy unwelcome magnetic resonance imaging may offer a reasonable alternative. The cost and availability of magnetic resonance imaging will prevent its widespread use. There is also a good chance that imaging will fail to show the cause of death and a necropsy will be required. Despite these drawbacks radiological investigations may be as valuable in death as they are in life.

Rob Bisset Consultant radiologist

$X$ Ray Department, North Manchester General Hospital, Manchester M8 6RB

\section{Depression as a risk factor for ischaemic heart disease in men}

\section{Two other community studies show similar findings}

EDitor-Hippisley-Cox et al showed the great potential of high quality general practice computer databases for use in epidemiological research in their elegant study of depression as a risk factor for ischaemic heart disease in men.

It has long been recognised that psychological symptoms are associated with an increased risk for physical disorders. ${ }^{2}$ The intimate connections between the nervous, endocrine, and immune systems provide a mechanism through which psychological changes can lead to changes in susceptibility to physical illness. ${ }^{3}$ In my experience, general practitioners are comfortable with the concept that feelings and events in people's lives can predispose them to just about any physical condition.

Hippisley-Cox et al suggest that research in this area has been limited to studies of small numbers of highly selected hospital patients, but there have been at least two long term community cohort studies. Barefoot and Schroll followed up a community sample of 730 participants over 27 years and showed that depression identified using psychological tests in earlier life was associated with a subsequent increase in mortality from myocardial infarction, in both men and women, over the whole range of severity of depressive symptoms. ${ }^{4}$ Pratt et al showed that dysphoria (two weeks of sadness) at interview in 1981 was associated with a twofold risk of myocardial infarction at follow up in 1994, and this was not related to the use of tricyclic antidepressants. ${ }^{5}$

Findings like these suggest that a history of depression should heighten doctors' suspicions when deciding whether or not to investigate symptoms that may represent ischaemic heart disease, regardless of whether they believe the relation to be causal. This is important since the temptation may be to ascribe a psychological origin to physical symptoms in the presence of depression.

Tony Kendrick Professor

Primary Medical Care, School of Medicine, University of Southampton, Aldermoor Health Centre, Southampton SO16 5ST

\footnotetext{
1 Hippisley-Cox J, Fielding K, Pringle M. Depression as a risk factor for ischaemic heart disease in men: population based case-control study. BMJ 1998;316:1714-9. (6 June.) Eastwood MR, Trevelyan MH. Relationship between physical and psychiatric disorders Ader R, Cohen N, Felten D. Psychoneuroimmunology: interactions between the nervous system and the immun

4 Barefoot JC, Schroll M. Symptoms of depression, acute myocardial infarction, and total mortality in a community sample. Circulation 1996;93:1976-80.

5 Pratt LA, Ford DE, Crum RM, Armenian HK, Gallo JJ Eaten WW. Depression, psychotropic medication, and risk of myocardial infarction-prospective data from the Baltimore ECA follow-up. Circulation 1996;94:3123-9.
}

\section{Key assumption about control group}

\section{undermines study's validity}

EDITOR-In their paper on the link between depression and ischaemic heart disease Hippisley-Cox et al made a key assumption about their control group that undermines the validity of their study. ${ }^{1}$ They assumed that controls are as likely as cases to receive a diagnosis of depression when one exists. I suggest that the cases who had ischaemic heart disease were much more likely to have received a diagnosis of depression than were the control group chosen.

The point prevalence for major depression in the general population is $5 \% .^{2}$ Many depressed patients do not consult their doctor, and about half of those who do will not have their diagnosis recognised. ${ }^{3}$ A further small proportion will have their depression detected in subsequent consultations. Patients with a recent diagnosis of ischaemic heart disease are likely to see their general practitioner on several occasions while diagnosis and treatment are secured. This means that their doctor is much more likely to detect their depressive illness than if they consult infrequently or not at all.

The control group chosen by HippisleyCox et al was not matched for the amount of 
doctor-patient contact or for the presence of a potentially life threatening condition. Selecting a control group in this way is highly likely to show higher rates of depression in the group with ischaemic heart disease, and that is indeed what the study found.

Geoff Earnshaw GP registrar

Town End Surgery, Caterham, Surrey CR3 5UJ

1 Hippisley-Cox J, Fielding K, Pringle M. Depression as a risk factor for ischaemic heart disease in men: population based case-control study. BMJ 1998;316:1714-9. (6 June.)

2 Paykel ES, Priest RG. Recognition and management of depression in general practice: consensus statement. $B M J$ 1992;305:1198-202.

3 Goldberg D, Huxley P. Mental illness in the community. The pathway to psychiatric care. London: Tavistock, 1980.

\section{Authors' reply}

EDITOR-Kendrick has drawn our attention to two cohort studies, both of which were published after our initial literature search in January 1996. Unfortunately we did not pick them up at a later stage. None the less, we are pleased to note that the findings broadly concur with ours, adding to the evidence for depression as a risk factor for ischaemic heart disease.

In answer to Earnshaw's first point, we studied the depression before the date of recorded diagnosis of ischaemic heart disease. As we described in the original paper, when depression was first diagnosed in the same year as the onset of ischaemic heart disease, it was assumed to have started after the onset of ischaemic heart disease. We did this to avoid possible confounding due to prodromal depressive symptoms which can occur immediately before myocardial infarction.

Earnshaw also criticises our choice of control group, stating that it was not matched for the presence of a potentially life threatening condition. However, we did take account of other major conditions - that is, diabetes and hypertension-by adjusting for them in the multivariate analysis.

Julia Hippisley-Cox Lecturer in general practice Mike Pringle Professor of general practice Division of General Practice, The Medical School, Queen's Medical Centre, Nottingham NG7 2UH

\section{Effectiveness of treatments for infantile colic}

\section{Dietary interventions in breast fed and bottle fed infants should not be pooled}

EDITOR-The pooled outcomes used in Lucassen et al's systematic review of treatments for infantile colic are not reported with their level of heterogeneity, but the three trials dealing with soy formula milk seem to be heterogeneous as the confidence intervals do not overlap. ${ }^{1}$ It may therefore be more useful to look at the differences between the three trials rather than pool the results. Excluding the trial of lower methodological quality does not seem to eliminate the heterogeneity.

The trial showing the large effect size (that by Campbell') is reported as having no babies who were partially or totally breast fed, while in the trial with the least effect (that by Evans et $\mathrm{al}^{3}$ ) all babies were breast fed. I wonder if this might explain the difference in outcomes.

The same reservation about pooling of the results would apply to the two trials of hypoallergenic formula milk. Although there seems to be no statistical heterogeneity between them, in that by Hill et al two thirds of the infants were breast $\mathrm{fed}^{4}$ and in the other (by Forsyth) none were breast fed. ${ }^{5}$ Pooling results from diet trials with such diverse levels of breast feeding may no make clinical sense; surely results from breast fed and bottle fed infants would be better analysed separately.

Christopher Cates General practitioner Manor View Practice, Bushey Health Centre, Bushey, Hertfordshire WD2 2NI

1 Lucassen PLBJ, Assendelft WJJ, Gubbels JW, van Eijk JTM, van Geldrop WJ, Knuistingh Neven A. Effectiveness of treatments for infantile colic: systematic review. $B M$ 1998;316:1563-9. (23 May.)

2 Campbell JPM. Dietary treatment of infantile colic: double-blind study.J R Coll Gen Pract 1989;39:1 1-4.

3 Evans RW, Fergusson DM, Allardyce RA, Taylor B. Maternal diet and infantile colic in breast-fed infant. Lancet 1981;i:1340-2.

4 Hill DJ, Hudson H, Sheffield LJ, Shelton MJ, Menhamen S, Hosking CS. A low allergen diet is a significant intervention in infantile colic: results of a coner based study. J Alleroy Clin Immunol 1995;94:886-92.

5 Forsyth BWC. Colic and the effect of changing formulas: double-blind, multiple-crossover study I Pediatr 1989; $115.251-6$.

Findings apply only to the most severely affected infants

EDITOR-I am concerned that the literature analysis by Lucassen et al may be used to make recommendations for the care of any infant reported to be colicky or to cry persistently. ${ }^{1}$ Indeed, the advice to start a one week trial of hypoallergenic formula is potentially harmful as some mothers may give up breast feeding-which is of proved benefit-for an artificial feed of unproved benefit. The authors have not made it sufficiently clear that the findings of the analysis apply only to the subgroup of infants with the most severe colic (those who meet a strict case definition and whose carer(s) are willing to participate in a clinical trial) and not to all infants who are reported to cry excessively.

Case definitions are important determinants of selection bias and hence generalisability. One of the main sources of bias in research into infantile colic has been the lack of an objective and universally applied case definition, and this has limited the possibilities for comparing the results of different studies as well as the generalisability of the results (table). ${ }^{2}$ Clever statistics are not a solution for bias, which has to be avoided through appropriate study design. The selection bias of the studies included in this analysis should be made explicit by detailed description of the populations studied and the case definitions used; it is not sufficient to state that trials were conducted in general practice or community based health services. In a large, unselected population based study of infantile colic, rates of infantile colic were higher in breast fed babies than bottle fed babies.. This argues

\section{Definitions of colic}

Duration and timing:

\begin{tabular}{|c|}
\hline$>3$ hours' crying a day on $>3$ days a week in any 1 week \\
\hline 3 hours' crying a day on 3 days a week for 3 weeks \\
\hline $\begin{array}{l}\text { Unexplainable periods of crying and restlessness, mostly } \\
\text { in the evenings }\end{array}$ \\
\hline$\geqslant 2$ hours' excessive crying a day \\
\hline$\geqslant 90$ minutes' excessive crying \\
\hline $\begin{array}{l}\geqslant 180 \text { minutes' distress in } 24 \text { hours when } 24 \text { hour } \\
\text { distress diary is used }\end{array}$ \\
\hline $\begin{array}{l}\text { Recurrent episodes of unexplained crying and irritability } \\
\text { that must have been present for at least } 1 \text { week in infants } \\
\text { aged } \leqslant 17 \text { weeks }\end{array}$ \\
\hline Evening colic; crying for $\geqslant 2$ hours in the evening \\
\hline 3 hours' crying a day for 1 week \\
\hline yndromes: \\
\hline $\begin{array}{l}\text { A behavioural syndrome characterised by excessive crying } \\
\text { that is paroxysmal in nature, more likely to occur in the } \\
\text { evenings, and without identifiable cause in an otherwise } \\
\text { healthy infant between } 2 \text { weeks and } 4 \text { months of age who } \\
\text { is difficult to console. Stiffening, drawing up of the legs } \\
\text { over the abdomen, and the passage of flatus are common } \\
\text { (although not invariable) accompaniments }\end{array}$ \\
\hline $\begin{array}{l}\text { Postprandial colic-three grades (not crying, occasional } \\
\text { crying or regular crying without pain, regular crying with } \\
\text { pain) }\end{array}$ \\
\hline iagnosis by parent or health visitor: \\
\hline Parent or health visitor reports colic (yes/no) \\
\hline
\end{tabular}

against cows' milk protein causing a large part of the burden of infantile colic in unselected populations.

Infantile colic by any definition has no adverse long term outcome for the infant. Any problems stem from the carer's frustration, sleeplessness, and distress. Nevertheless, because most researchers are grounded in the medical model of disease their approach has focused on finding a way to "cure" the infant of this "disease."

Natasha Crowcroft Senior registrar in public health medicine

20 Beauval Road, London SE22 8UQ

1 Lucassen PLBJ, Assendelft WJJ, Gubbels JW, van Eijk JTM van Geldrop WJ, Knuistingh Neven A. Effectiveness of treatments for infantile colic: systematic review. BMJ 1998;316:1563-9. (23 May.)

2 Crowcroft NS. Infantile colic. London: Faculty of Public Health Medicine of the Royal College of Physicians, 1995. [Dissertation submitted for part 2 of the examination for membership of the faculty.]

3 Crowcroft NS, Strachan DP. The social origins of infantile colic. BMJ 1997;314:1325-8.

\section{Trial of hypoallergenic milk is not} supported by strong enough evidence

EDITOR-It is encouraging to see a subject that troubles so many parents-infantile colic-put through the rigours of a systematic review to find effective treatments. ${ }^{1}$ This review could, however, be more explicit, as it concentrates on colicky babies fed artificial formula. In addition, the two trials of hypoallergenic milks on which the conclusions are based are small.

The study by Forsyth seems to have had a drop out rate of $47 \%$, with only 17 babies accounted for. ${ }^{2}$ The babies, who were all bottle fed, were given feeds over four day periods alternating between a standard formula and hypoallergenic milk, and the mothers kept a diary of crying episodes caused by colic. The abstract of this study states that only in one baby was a clinically 
meaningful response reported with all three formula changes. The article concluded that the effect of hypoallergenic milk diminishes with time and is only rarely reproducible. Hill et al studied 38 bottle fed babies and 77 breast fed babies, whose mothers were treated with a diet free of artificial colours and preservatives; the breast feeding mothers were also randomised to a treatment diet that excluded milk, eggs, wheat, and nuts or a control diet. ${ }^{3}$ The statistical results seem to include both these groups of babies together. Were they separated for this systematic review?

I am concerned that the recommendation of a one week trial of hypoallergenic milk as a treatment for infantile colic for babies receiving cows' milk formula is not supported by strong enough evidence. Other recommendations listed are less debatable-listening to and supporting parents, offering reassurance, etc-although the suggestion to avoid carrying and holding for long periods seems contrary to instinct. A discussion on treatments for breast fed babies with colic would be useful.

Phyll Buchanan Supporter of breast feeding Breastfeeding Network, PO Box 11126, Paisley PA2 8YB

113327.1544@compuserve.com

1 Lucassen PLBJ, Assendelft WJ, Gubbels JW, van Eijk JTM, van Geldrop WJ, Knuistingh Neven A. Effectiveness of treatments for infantile colic: systematic review. $B M J$ 1998;316:1563-9. (23 May.)

2 Forsyth BWC. Colic and the effect of changing formulas: a double-blind, multiple-crossover study. J Pediatr 1989; 115:251-6.

3 Hill DJ, Hudson H, Sheffield LJ, Shelton MJ, Menhamen S, Hosking CS. A low allergen diet is a significant intervention in infantile colic: results of a communitybased study. J Allergy Clin Immunol 1995;94:886-92.

\section{Authors' reply}

EDITOR-As Cates rightly assumes, the three trials dealing with soy formula milk are heterogeneous: a test of heterogeneity yielded $\mathrm{P}<0.05$. One can try to explain heterogeneity, ignore it (fixed effects model), or model it (random effects model). We used a random effects model in the pooling process. Despite the statistical heterogeneity we pooled the results of the individual trials; we judged differences in the definition of colic, outcome measures, and duration of intervention to be small enough for pooling to be allowed. This judgment is subjective, but both breast fed and bottle fed colicky infants experience the same (assumed) pathophysiological process, the same intervention (elimination of cows' milk proteins), and the same outcome (reduction of crying); the different reasons why parents decide to breast feed or bottle feed are not important here. We agree with Crowcroft's remarks about the one week trial of hypoallergenic formula and the lack of uniform definitions of infantile colic. Excessive crying, however, is the most important characteristic in all definitions. Additional symptoms are infrequently assessed in studies on this subject. In our systematic review we aimed to produce results for very different interventions on a common scale, thereby (subjectively) assuming that in essence the same underlying problem (excessive crying) was studied. The definition of infantile colic assumes a healthy, thriving infant. The assessment of health is not, however, straightforward, as a thriving infant with normal findings on physical examination might, several days later, be diagnosed as having cows' milk allergy or glenohumeral arthritis. ${ }^{1}$ Therefore, instead of the words "infantile colic" we prefer to redefine the problem according to the definition of Carey $^{2}$ and to distinguish normal crying, secondary excessive crying (for example, that caused by cows' milk allergy), and primary excessive crying. A one week trial of a hypoallergenic formula should be seen as a diagnostic test to rule out cows' milk allergy. In breast fed infants the mother should eliminate cows' milk proteins from her diet. We did not mean to suggest that breast feeding should be stopped. We agree with Buchanan that the recommendations on hypoallergenic formula are based on small trials, but this is the best available evidence. We did not present the results for breast fed and bottle fed infants separately as we assumed that the same underlying mechanisms operated. The advice for a one week trial of hypoallergenic formula does not imply that breast feeding should be stopped. We chose to compare the number of clinically meaningful responses to hypoallergenic formula and cows' milk formula in Forsyth's study. ${ }^{3}$ If both treatments are equally effective it is to be expected that both kinds of treatment changes cause an equal number of clinically meaningful responses. We recognise, however, that more attention could have been given to the lack of consistency in time.

P L B J Lucassen General practitioner lucassen@knmg.nl

W JJ Assendelft General practitioner

J T M van Eijk Professor of general practice

Institute for Research in Extramural Medicine, Free University, Amsterdam, Netherlands

J W Gubbels Statistician

Organisation for Research and Policy Advice, Grave, Netherlands

W J van Geldrop General practitioner Scientific Committee of the Dutch College of General Practitioners, Utrecht, Netherlands

A Knuistingh Neven General practitioner Department of General Practice, University of Leiden, Leiden, Netherlands

1 Lucassen PLBJ. Infantile colic in primary care. OccurLucassen PLBJ. Infantile colic in primary care. Occur-
rence, causes, treatments [dissertation]. Amsterdam: Free rence, causes, tre

2 Carey WB. "Colic"-primary excessive crying as an infantCarey WB. "Colic"-primary excessive crying as an infantenvironment

31:993-1005

3 Forsyth BWC. Colic and the effect of changing formulas: double-blind, multiple-crossover study. J Pediatr 1989 115:251-6.

\section{Embryonic abnormalities at medical termination of pregnancy}

\section{Results could be explained by misinterpretation of macroscopic appearances}

EDITOR-I have serious doubts about the validity of the data reported by Blanch et al on embryonic abnormalities at medical termination of pregnancy. ${ }^{1}$ In my experience, embryos are delicate and can be readily disrupted even during careful handling. Although the authors state that "strict criteria were used to distinguish structural abnormalities from traumatic damage," they give no details of these criteria and whether they have been generally accepted as distinguishing between trauma and abnormality in delicate embryonic tissue. I believe that it is important to specify in how many cases traumatic damage was seen.

Although Blanch et al state that macroscopically abnormal embryos were further examined histologically, they do not report the histological findings and I was surprised that a pathologist was not included as an author. Were all the neural tube and abdominal wall defects confirmed histologically? It is easy to envisage how compression of a delicate embryo during delivery might induce rupture of both the abdomen and central nervous system.

An anembryonic pregnancy rate of $23 \%$ (48 in 206 cases) before 9 weeks of pregnancy is high in comparison with the rate of $16 \%$ found in a study of 38 abnormal early pregnancies ${ }^{2}$ and that of $1 \%$ in an ultrasound study of 17820 normal pregnancies (albeit 10-13 weeks' gestation). ${ }^{3}$ Such a discrepancy must be explained.

I believe that the unexpected finding of a $34 \%$ non-viable pregnancy rate can be explained by misinterpretation of macroscopic appearances.

Michael Jarmulowicz Consultant histopathologist Department of Histopathology, Royal Free Hospital School of Medicine, Royal Free Hampstead NHS Trust, London NW3 2QG

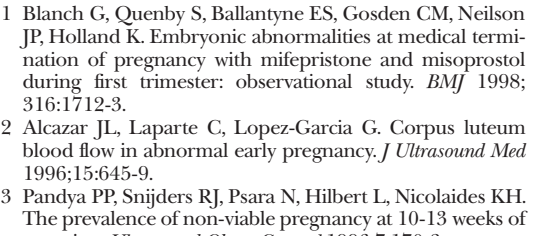
JP, Holland K. Embryonic abnormalities at medical termiJP, Holland K. Embryonic abnomities at medical termination of pregnancy with mifepristone and misoprostol during

2 Alcazar JL, Laparte C, Lopez-Garcia G. Corpus luteum blood flow in abnormal early pregnancy.J Ultrasound Med 1996;15:645-9

3 Pandya PP, Snijders RJ, Psara N, Hilbert L, Nicolaides KH. The prevalence of non-viable pregnancy at 10-13 weeks of gestation. Ultrasound Obstet Gynecol 1996;7:170-3.

\section{Authors' reply}

EDitor-Most (80\%) of the embryos that we examined were delivered within intact gestation sacs, protected from trauma by the amniotic fluid and membranes, and without any sign of tissue disruption macroscopically, microscopically, or histologically. In the $20 \%$ of pregnancies in which the gestation sac had ruptured during abortion we used strict histological criteria to distinguish structural abnormalities from traumatic damage. Three investigators studied each embryo independently before a classification was determined; when a neural tube defect was suspected on macroscopic inspection, the periderm (future dermis) was examined meticulously and the embryo was classed as having a neural tube defect only if the skin surface was continuous with the developing neural tissue; abdominal wall defects were diagnosed only if there were loops of bowel outside the abdominal wall before Carnegie stage 16 or if other 
intra-abdominal organs such as the liver were outside the abdominal wall and if the edge of the periderm was histologically rounded rather than ragged.

Anembryonic pregnancy was diagnosed only when the gestation sac was intact. We found an incidence of 33 out of $206(16 \%)$. This is identical with the rate of anembryonic pregnancy quoted by Alcazar et al. ${ }^{1}$ In our study, the pregnancies were $6-9$ weeks' gestation. The discrepancy between the anembryonic pregnancy rate in our study and that in the study by Pandya et al $(1 \%)^{2}$ can be explained by the fact that most anembryonic pregnancies would have ended in miscarriage by 10-13 weeks' gestation in the other study.

We are confident that our methods did not overestimate the incidence of pregnancy abnormality.

Siobhan Quenby Lecturer

Geraldine Blanch Senior registrar

James Neilson Professor of obstetrics and gynaecology Department of Obstetrics and Gynaecology,

University of Liverpool, Liverpool L69 3BX

1 Alcazar JL, Laparte C, Lopez-Garcia G. Corpus luteum blood flow in abnormal early pregnancy. J Ultrasound Med 1996;15:645-9.

2 Pandya PP, Snijders RJ, Psara N, Hilbert L, Nicolaides KH. The prevalence of non-viable pregnancy at 10-13 weeks of gestation. Ultrasound Obstet Gynecol 1996;7:170-3.

\section{Detection of changes in mortality after heart surgery}

\section{Control limits failed to account for case} mix

EDITOR-We are concerned about the graphical technique described by Poloniecki et al in their analysis of perioperative mortality rates associated with cardiac surgery. ${ }^{1}$ Figure 2 shows three traces: observed mortality performance bracketed by control limits and plotted against the number of successive cases performed. The interpretation of the middle of the traces is straightforward since it is simply a variable life adjusted display that has previously been described and will be familiar to many cardiac surgeons in the United Kingdom. ${ }^{2}$ The use of control limits, on the other hand, is new. However, the usefulness and indeed the validity of these is not clear. As the authors themselves note, their analysis does not amount to a formal test of significance since the control limits have not been corrected for multiple testing; this is a major deficiency. The use of $99 \%$ control limits rather than $95 \%$ control limits presumably increases their separation and makes them more forgiving. It is not clear which level of significance should be used, a difficulty compounded by the fact that the limits are not based on formal significance testing.

Hypothetical operations on two groups of patients with different mortality risks

\begin{tabular}{lccc} 
Case load & Preoperative estimate of mortality risk (\%) & $\begin{array}{c}\text { Predicted } \\
\text { No of deaths }\end{array}$ & $\begin{array}{c}\text { Exact 99\% limits on } \\
\text { No of deaths }\end{array}$ \\
\hline Sequence $1(n=1000)$ & 40 patients with $72 \%, 960$ patients with $0.125 \%$ & 30 & 22 to 38 \\
\hline Sequence $2(n=1000)$ & 1000 with $3 \%$ & 30 & 17 to 45
\end{tabular}

If we understand correctly, these control limits have been calculated using a $\chi^{2}$ distribution. However, this fails to take into account case mix and heterogeneity of risk, the very things for which variable life adjusted display plots are used. The following example illustrates the danger in ignoring case mix when estimating ranges of variability. Consider operations on two sequences of 1000 patients with different underlying mortality risks that have been assessed preoperatively (table). Based on the given mortality risks, there is a $99 \%$ probability that the number of deaths that actually occur would fall in the range shown in the last column. These ranges are derived from exact calculations based on the binomial expansion. Using a $\chi^{2}$ distribution would give a range (16 to 44 ) close to the exact values obtained for the patients in sequence 2 , for whom no heterogeneity of risk is present, but would substantially overestimate the range for the patients in sequence 1 , for whom risks are heterogeneous.

When examining surgical mortality, it is important to take case mix into account However, this should be done not only when estimating the expected mortality but also when estimating the likely variability. Any overestimation of likely ranges of variability might well lead to undue complacency.

Steve Gallivan Director, Clinical Operational Research Unit

Department of Mathematics, University College London, London WC1E 6BT

Jocelyn Lovegrove Research fellow

Christopher Sherlaw-Johnson Senior research fellow Clinical Operational Research Unit, University

College London

1 Poloniecki J, Valencia O, Littlejohns P. Cumulative risk adjusted mortality chart for detecting changes in death rate: observational study of heart surgery $B M J$ 1998:316:1697-700. (6 June)

2 Lovegrove J, Valencia O, Treasure T, Sherlaw-Johnson C, Gallivan S. Monitoring the results of cardiac surgery by variable life-adjusted display. Lancet 1997;350:1128-30.

\section{Author's reply}

EDITOR - In order not to generate confusion when referring to the cumulative risk adjusted mortality chart, I suggest that Gallivan et al stick to the original name for this plotting technique, which I gave it in 1995 . Further details of the precedent are set out at the end of our paper.

Unfortunately Gallivan et al are not alone in the practice of claiming that a surgeon is worse than his or her colleagues, or that a colleague's performance has deteriorated (and then improved), without any statistical basis for the assertion-that is, without consideration of the rate of false positives. ${ }^{1}$

The potential usefulness of control limits is no doubt clear to Gallivan et al. In their paper they state: "Some work on the

BMJ VOLUME 31721 NOVEMBER 1998 www.bmj.com statistical approach to this question has been done (Jan Poloniecki, unpublished observations). ${ }^{1 . "}$ Their haste to submit the same data with the same plotting technique to the same journal at the same time may be responsible for the fact that reference 13 has been omitted from the list of references published in the Lancet. ${ }^{1}$

Gallivan and his colleagues at University College London are right in thinking that nominal 99\% control limits will give wider confidence intervals, and therefore fewer false positive results, than $95 \%$ limits based on the same test. If, as we have suggested should happen, a formal internal inquiry is launched whenever the statistical control limits are breached, then the confidence limits must be wide enough to ensure that this does not occur so often as to be unmanageable. For our series, we found that the control limits for the cumulative risk adjusted mortality were breached at most twice in nearly four years. The second occasion was particularly transient-that is, self-correcting-and might not have occurred at all if any of the parameters had been reset after the first occasion.

Gallivan et al suggest that the test could be based on a multinomial distribution. Both 0 and $100 \%$ are valid Parsonnet scores, and with these risk estimates the multinomial confidence limits have a width of 0 . None the less, they could try their suggestion on, for example, the St George's data, which they have, to find out how often the control limits for the cumulative risk adjusted mortality chart are breached.

J D Poloniecki Lecturer in statistics Department of Public Health Sciences, St George's Hospital Medical School, London SW17 ORE

1 Lovegrove J, Valencia O, Treasure T, Sherlaw-Johnson C, Gallivan S. Monitoring the results of cardiac surgery by variable life-adjusted display. Lancet 1997;350:1128-30.

\section{Son's reaction to his circumcision was predictable}

EDITOR-We should expect better from a person with McFadyen's training.' Circumcision is an unnecessarily radical, traumatic, and invasive procedure for a simple problem. Several researchers have found a more conservative approach satis factory. All that is necessary is to lyse the adhesions under some type of anaesthesia, with application of petroleum jelly to prevent readhesion during the healing period. ${ }^{23}$

Even more troublesome is McFadyen's surprise at her son's emotional reactions to his penile surgery. The traumatic nature of genital surgery has been known from the time of Freud, who coined the term "castration anxiety." There are ample reports in the analytical literature of the traumatic effects of circumcision. ${ }^{4}$ A thorough airing of the trauma of circumcision has recently appeared in a book. ${ }^{5}$ There should have been no surprises.

George Hill Member, National Organization of Circumcision Information Resource Centers of Louisiana

Port Allen, Louisiana, USA

Gh44444@aol.com 
1 McFadyen A. Children have feelings too. BMJ 1998;316:1616-8. (23 May.)

2 Cooper GB, Thompson GJL, Raine PAM. Therapeutic retraction of the foreskin in childhood. $B M J$ 1983;286:186-7.

3 MacKinlay GA. Save the prepuce. Painless separation of preputial adhesions in the outpatient clinic. $B M J$ 1988;297:590-1.

4 Cansever G. Psychological effects of circumcision. Br J Med Psychol 1965;38:321-31.

Goldman R. Circumcision: the hidden trauma. Boston: Vanguard, 1997

\section{Professional and practice development plans for primary care teams}

\section{Academic GPs should not be ones to decide whether service GPs are fit to continue}

EDIToR-Elwyn's editorial about professional and practice development plans for primary care is at best confused and at worst dangerous. ${ }^{1}$ He comments that there are good and bad practices and points to the difference between the (apparently) good and the (obviously) bad. The good are paperless, with nurse practitioners, physiotherapists, and on site phlebotomists; the bad are those where consultations are perfunctory, prescribing suspect, and the sole aids are prescription pads, sick notes, and unchecked sphygmomanometers.

What evidence does he have that being paperless or having a nurse practitioner leads to better patient care? My practice has an on site physiotherapist, but this doesn't make us a better practice, just slightly more convenient for patients. Neither does our computer make us a better practice. This false logic is part of an insidious trend: if you don't have all the above trappings plus a nurse facilitator doing your audit and a business plan then you're no good. I'm sure that patients don't see it this way. The truth is that however much academic general practitioners try to tinker with general practice, with their talk of practice development, the patients will still be there with the same problems, and it is our job to be available and accessible, to listen, diagnose, treat, or refer and to give appropriate support. Elwyn fails to mention any of these things, which are more important than the esoteric matters with which he is preoccupied.

Why do we need practice reaccreditation? We've all passed our exams after years of hard work, and, except for a small number of black sheep, we're all doing our best for our patients. Lawyers, accountants, engineers, architects, dentists, and vets aren't flagellating themselves in this way. Voluntary "personal learning plans" are OK if you want them. I know that the meetings that I choose to attend and for which I get postgraduate education allowance are helpful to me and my patients, but trying to prove this for reaccreditation purposes would be difficult and is unnecessary. Some things just have to be taken on professional trust. It's the crafty link between personal learning plans and reaccreditation that general practitioners must be most wary of. Full time service general practitioners (as the academics call them) don't need people like Elwyn deciding annually whether they are fit to continue practising. Elwyn's editorial is really about a small number of general practitioners trying to assert control over the rest of us. General practitioners will let this happen at their peril.

John Eggleton Principal in general practice Delph House Surgery, Exeter EX4 7HL

1 Elwyn GJ. Professional and practice development plans for primary care teams. BMJ 1998;316:1619-20. (30 May.)

\section{Network of GP tutors is well placed to facilitate change}

EDITOR-The chief medical officer's review of continuing professional development in general practice ${ }^{1}$ has been long awaited by educationists. As Elwyn points out, it will add impetus to the move towards a "corporate" rather than "independent practitioner" vision of primary care. ${ }^{2}$ It should, however, be introduced with care. General practitioners must be informed fully about the proposed changes, which should be introduced with the support of the networks of general practice tutors. Many general practitioners continue to feel aggrieved at the imposition of the current postgraduate education allowance system.

I have presented the findings of the review at several meetings, and they have been received with disdain by many general practitioners. These general practitioners mainly agree that the organisation of the continuing professional development of their primary healthcare teams is in disarray, but they are reluctant to cooperate with any change to the present system while what they believe is their income (the postgraduate education allowance) is threatened. I agree with Elwyn that the change would be more readily accepted if the allowance was preserved as net income.

My main concern relates to the suggestion that the acceptance of a practice professional development plan by the health authority triggers payment of the postgraduate education allowance. The postgraduate general practice education organisations must be responsible for accreditation, as they have built up valuable expertise since the introduction of the allowance. The network of general practice tutors is in an ideal position to facilitate the change and support the general practitioners in completing their annual practice professional development plans.

At the West Midlands Postgraduate General Practice Education Unit we have adapted our postgraduate education allowance accreditation system to promote individual learning plans and personal learning. We have also developed an ambitious mentoring scheme and have provided funds to enable some practices to develop their own learning plans by supporting educational activities.
My own practice is piloting a practice professional development plan. The health authority has ring fenced the staff and nurse training budgets as a first step, and its training adviser is on the steering committee. The plan has been formulated by a multidisciplinary group, but we also respect the needs of individuals and their professional groupings. The general practitioners are now satisfied that they will not lose income to support the other staff, and the plan is moving ahead. The plan incorporates the practice's audit and research activity and reflects the agreed quality issues and performance indicators. We aim to publish a report at the end of the first year.

Steve Field Director of postgraduate general practice education, West Midlands

Postgraduate General Practice Education Unit, Birmingham B15 3DP

s.field@bham.ac.uk

1 Department of Health. A review of continuing professional development in practice: a report by the chief medical officer. London: Department of Health, 1998

2 Elwyn GJ.Professional and practice development plans for primary care teams. BMJ 1998;316:1619-20. (30 May.)

\section{Scheme with little funding and no} protected time will be forced on GPs

EDITOR-As a general practitioner who enjoys his work and takes pride in his specialty I had to ask myself why my heart sank as I read the editorial by Elwyn. ${ }^{1}$ Am I more cynical than I think? Do I deny the need for me and my colleagues in our primary care team to learn and develop professionally? No. I realised that the answer lay outside the team. I know that the reality will be a scheme with little or no funding and no protected time, forced on us against a background of ever increasing demand and continuing failure to develop the team to carry out its existing workload, let alone a new task. Of course the great and the good will tell us that it is essential for us to grasp this nettle, while the academic departments will bombard us with glossy brochures offering to provide a tailored service at reasonable rates. The general practitioners will cobble something together, miss another few lunches, and pick up the tab.

Nothing new there, then.

Martin McCloskey General practitioner

Aberfoyle Medical Practice, Derry BT48 7PB

1 Elwyn GJ. Professional and practice development plans for primary care teams. BMJ 1998;316:1619-20. (30 May.)

\section{Didactic teaching by specialists can be} stimulating and effective

EDITOR-In his editorial about professional and practice development plans for primary care teams Elwyn makes two astounding assertions. ${ }^{1}$ The notion that didactic teaching is effectively dead surely requires a challenge. There may be occasions when learning with other members of our practice team is both relevant and helpful, but for 
most of the time I, and I suspect many other general practitioners, have found regular updates from acknowledged specialists to be both stimulating and effective in the battle to keep abreast of various subjects. The idea that this established and popular method of teaching could now be replaced by activities that will doubtless include role play, group work, and plenary sessions fills me with gloom. For too long whole sections of the medical establishment have blindly endorsed such a teaching system without ever trying to understand the antipathy and even hostility that it generates.

The chief medical officer is, apparently, promoting the "corporate" rather than the "independent practitioner" vision of general practice. Presumably this idea comes from people living in the same ivory tower as those whose understanding of the nuances of general practice was so admirably shown in the pill scare of two years ago. I have difficulty squaring this corporate ideal with what I still think is a most appropriate definition of general practice and one that encapsulates much of our work even though it was written 35 years ago: "The family doctor must interpret the patient, his problem and circumstances to the consultant, explain the need for hospital service and its possibilities to the patient and ensure the necessary communication with all concerned including the relatives."

General practice must wake up. The so called jewel in the crown of the NHS is under threat of being dismantled; perhaps we have already reached the stage of no return when the author of this editorial is able to write a sentence such as "Effective strategies also use contextual and motivational influences."

Frank Akerman General practitioner Alma Road Surgery, Romsey, Hampshire SO51 8ED

almaroad@enterprise.net

1 Elwyn GJ. Professional and practice development plans for primary care teams. $B M J$ 1998:316:1619-20. (30 May)

2 The field work of the family doctor. London: HMSO, 1963. (Gillies report.)

PGEA system has resulted in great achievements in general practice education

EDitoR-Elwyn's editorial on the chief medical officer's paper on continuing professional development in general practice falls into the trap of taking the populist view of the postgraduate education allowance as being a didactic, ineffective, and topdown system of education that has benefited no one other than the pharmaceutical industry. ${ }^{1}$ It also ignores the important fact that the proposed professional-practice education plan merely builds on the ideas of self directed learning in general practice education that were introduced through the postgraduate education allowance as long ago as $1991 .^{2}$

The postgraduate education allowance system has its flaws, and now is probably the right time to move on; but it would be wrong to ignore the remarkable achieve- ments of general practice education since its introduction. For the first time general practitioners were treated as adult learners given responsibility for their own personal and professional development. They could choose from a menu of educational opportunities that reflected their educational needs and their preferred learning style. There is nothing inherently wrong with didactic teaching as long as it is appropriate to the subject and is not the only form of teaching. Although a few doctors may have attended a meeting just to get the postgraduate education allowance points, most took advantage of distance learning programmes, modular degree courses, practice based educational activities (often multiprofessional), and exciting personal education plans (in Yorkshire alone we have had some 200 completed personal/practice education plans over the past seven years). We have also developed reasonable expertise in standard setting and monitoring of accredited education. This will probably be enormously important to the future of reaccreditation and recertification in general practice. And all that has been achieved at little extra cost to taxpayers.

I hope that "life after the postgraduate education allowance" will not be about reinventing the wheel but about learning from our experience and building on what we have learnt. Please do not throw the baby out with the bath water. Especially if the water is clean and the baby happy.

Jamie Bahrami Director of postgraduate general practice education

Department for NHS Postgraduate Medical and Dental Education (Yorkshire), University of Leeds, Leeds LS2 9JT

1 Elwyn GJ. Professional and practice development plans for primary care teams. BMJ 1998;316:1619-20. (30 May.)

2 Bahrami J, Rogers M, Singleton C. Personal education plan: a system of continuing medical education for genera practitioners. Educ Gen Pract 1995;4:342-5.

\section{Reducing radon levels}

\section{Responsibility should be with local authority}

EDIToR-We now have direct evidence that residential exposure to radon in the United Kingdom causes lung cancer. ${ }^{1}$ This removes one large hurdle on the route to effective preventive action.

Radon remediation is based on good epidemiology, is cost effective, and, because the problem is small, is affordable. The target population (houses) is well defined and immobile. It does not suffer the pragmatic obstacles of smoking or water fluoridation-no civil liberties issue is at stake, the remedy is not addictive, nobody is advertising the remedy. But it lacks strong advocacy and coordination of the efforts of society, and remediation has been delayed and incomplete. ${ }^{23}$ Because of high costs to individual householders the results of tests are confidential, and monitoring remedial action is difficult.

Achieving change will mean using the new study that Wise reports to influence decision making at the level at which it is being taken. ${ }^{1}$ Currently this is divided between residents, landlords, local authorities, health authorities, and the government. Residents and landlords have to make an immediate investment for a long term benefit against competing priorities ${ }^{4}$ and face a moral hazard that delaying action may be rewarded by more central subsidy or lower costs.

The benefits in the built environment accrue more to society than to the current occupier, and the operation of the free market is likely to accentuate health inequalities. Further exhortation of individuals, without mandatory help, ${ }^{2}$ is the public health option least likely to work. The National Radiological Protection Board has provided good information for 10 years, but remedial action has not always followed.

Responsibility should be placed clearly at a single level (probably the local authority, though Our Healthier Nation suggests the health authority ${ }^{5}$ ) and central government should recognise the unequal financial burden that the distribution of radon in dwellings imposes on these authorities.

Michael Peter Le Geyt Senior house officer in accident and emergency

Milton Keynes General Hospital, Milton Keynes MK6 5LD

1 Wise J. Radon may account for one in 20 cases of lung cancer. BMJ 1998;316:1557. (23 May)

2 Jukes G. Action needed to prevent deaths from radon. Environ Radon Newsletter 1996;8:3.

3 Taylor M. The new affected areas. Environ Radon Newsletter 1996;8:3.

4 Webb J. Radon in council houses: a shrinking problem. Environ Radon Newsletter 1995;3:4

5 Department of Health. Our healthier nation: a contract for health. London: Stationery Office, 1998

\section{Householders are not prepared to pay}

EDitor-Wise talks about the recent report on the risks of radon, ${ }^{1}$ and we were interested to see the electronic response to her article by Le Geyt. ${ }^{2}$ In Northamptonshire, one of the areas affected by radon, we have estimated the cost effectiveness of radon remediation programmes. We have shown that programmes in the NHS workplace and domestic properties in Northamptonshire are more cost effective than the National Radiological Protection Board's recent proposals to reduce patient doses in dental radiology. ${ }^{34}$ These are the first reports of the cost effectiveness of actual radon remediation programmes and are similar to theoretical estimates.

It is four times more cost effective to remediate houses than the workplace if every house is remediated. In reality only around $35 \%$ of houses have been tested in Northamptonshire, and only a tenth of householders finding raised radon levels organise remedial work. Because of this the cost effectiveness for houses is greatly reduced and similar to that in the NHS workplace.

Most houses in Northamptonshire were tested during government sponsored free testing, but remediation costs fall to the householder. Thus the government is getting poor value for money even if the 
programme can still be justified at a $10 \%$ take up. Our work showed that a considerable proportion of householders whose homes have radon levels just above the action level decide not to proceed to remediation, presumably because they think that the moderate risk does not justify the expense. We have also spoken to several retired house owners, who argue that it is not worth remediating their homes. We have found that staff expect raised radon levels in the workplace to be remediated immediately but are reluctant to spend money to investigate and remediate their own home, even though they could be at greater risk in the home.

In Northamptonshire we expect that more houses will be remediated now that surveyors ask about radon testing at the time of a sale. Sweden, where there is a legal requirement for householders to reduce radon levels, has achieved $40 \%$ remediation. Despite local publicity, builders of new houses in Northamptonshire, who now install radon-proof membranes under the building regulations, prefer not to mention the radon risk to purchasers from outside Northamptonshire; they fail to advertise that they comply with the required standards and that purchasers are safe. How can we encourage the public to take radon seriously?

Antony Denman Head of medical physics

Northampton General Hospital, Northampton NN1 5BD

Paul Phillips Senior lecturer

Nene University College, Northampton NN2 7AL

1 Wise J. Radon may account for one in 20 cases of lung cancer. BMJ 1998;316:1557. (23 Mav.)

2 Le Geyt MP. Radon: case for a public health campaign www.bmj.com/cgi/eletters/316/7144/1553/I; EL1. (Published above.)

3 Denman AR, Barker SP, Parkinson S, Phillips PS. The health benefits and cost effectiveness of the radon mitigation programme in NHS properties in Northamptonshire. J Radiol Prot 1997;17:253-9.

4 Denman AR, Phillips PS. A review of the cost effectiveness of radon mitigation in domestic properties in Northamptonshire. J Radiol Prot 1998;18:119-24.

\section{Mentioning smoking as a cause of death on death certificates}

\section{Relatives can be asked in death registries} about smoking habit of dead person

EDITOR-Robinson et al report that most British doctors do not put smoking as a cause of death. ${ }^{1}$ We should recognise, however, that doctors will have difficulty in identifying a clear link between smoking and death in individual patients. The recommendation in the report of the Scientific Committee on Tobacco and Health that smoking status should be "recorded as part of the death registration process to aid monitoring the evolving epidemic of tobacco related diseases" is more practical. ${ }^{2}$ We agree that smoking status should be recorded on all death certificates and not only as a specified cause of death, but further legislative changes to introduce this will incur further delays. We cannot expect more than one additional question in the certificate, and this should ask whether the dead person had been a regular smoker. A smoking history should be available in the medical record, but if it is not then the doctor should ask the relatives. Whether doctors are prepared to do this reliably is questionable and needs further study.

In a large case-control study in China the smoking habits of people who had died were obtained from their surviving spouses in home interviews a few years after the death, ${ }^{3}$ but this method is expensive. As a quick alternative we are obtaining information on the smoking habit of people who have died by interviewing their relatives at death registries. This has been part of a case-control study throughout 1998. ${ }^{4}$ Relatives approaching a registration counter are invited to complete a questionnaire about the person who has died and about a control, who can be a surviving spouse or another living relative. The process takes only 10-15 minutes while the person waits for the death certificate. All people who have died at the age of $\geqslant 30$ are included.

Up to 5 October 1998 information on smoking habit at about 10 years before death was obtained from all death registries in Hong Kong for 11632 male and 9464 female people who had died. Ninety four per cent of the relatives were willing to participate. Altogether $8032(69 \%)$ of the men and 2052 of the women who had died had smoked. Attributable risks due to smoking can be calculated by comparing the smoking status of the dead subjects with that of the controls. We conclude that this method is cheap, efficient, and acceptable to the relatives and that it has potential for immediate implementation in other countries, particularly those where death certification is unreliable.

T H Lam Professor

S Y Ho Researcher

A J Hedley Professor

Department of Community Medicine, University of Hong Kong, Hong Kong, China

hrmrlth@hkucc.hku.hk

K H Mak Consultant in community medicine

Department of Health, Wanchai, Hong Kong, China

1 Robinson L, Spencer J, Stacy R, Bhopal R. Smoking should be mentioned as a cause of death on death certificates. $B M$ 1998;316:1606. (23 May.)

2 Scientific Committee on Tobacco and Health (chairman D Poswillo). Report. London: Department of Health, Department of Health and Social Services, Northern Ireland, ment of Health and Social Services, Northern Ireland, Scottish Ofice Department of Health, Welsh Office, 1998. Liu BQ, Peto R, Chen ZM, Boreham J, Campbell C, Chen JS, et al. Nationwide case-control study of smoking and deaths in China. In: Abstract book, 10th world conference on tobacco or health, Beijing, 24-8 Aug 1997:27.

4 Ho SY, Lam TH, Hedley AJ, Mak KH. A pilot study on mortality and smoking in Hong Kong. In: Abstract book, 10 th world conference on tobacco or health, Beijing, 24-8 Aug 1997:113

\section{Relatives don't like this being done}

EDITOR-Robinson et al suggest that smoking should be listed as a cause of death on death certificates. ${ }^{1}$ In 1992, as a senior house officer in respiratory medicine, I began to do this. Within a few weeks it led to several complaints from distressed relatives, who inferred that doctors were apportioning blame to the person who had died. In one case I was even asked to reissue a certificate, with smoking removed from the causes of death. I have not since attempted to put smoking on death certificates, and I suspect that my experiences were not unique.

Paula Johnson Specialist registrar in respiratory medicine

Pilgrim Hospital, Boston, Lincolnshire PE21 9QS

mmxphj@mmn1.medical.nottingham.ac.uk

1 Robinson L, Spencer J, Stacy R, Bhopal R. Smoking should be mentioned as a cause of death on death certificates. $B M J$ 1998:316:1606. (23 May)

\section{Royal Medical Benevolent Fund reminds readers of its Christmas appeal}

Editor-Christmas is one of the happiest times for most of us. Those who this year look forward to sharing the festivities within a family circle have much to be grateful for. Unfortunately, for some others this time of year can, by contrast, bring sadness. Those working on doctors' behalf in the Royal Medical Benevolent Fund know only too well of the unexpected tragedies within our profession and the resulting hardship-all the more poignant when young children are involved. The fund always seeks to give a little extra help at Christmas time.

I have been president for less than a year, but I am well aware of the fund's Christmas appeal. For the first time, however, I now understand its success. Thanks to doctors' generosity it has done well financially. Success, though, can be measured in other ways-for example, by perusal of some of the many charming letters of thanks. These have given me a clearer understanding of the great need and why each year we must strive for still greater success.

Contributions marked "Christmas appeal" may be sent to the secretary of the Royal Medical Benevolent Fund at the address below or to the treasurer or medical representative of readers' local guild of the fund.

Rodney Sweetnam President

Royal Medical Benevolent Fund, London SW19 8QN

\section{Correction}

Odds ratios should be avoided when events are common

Several errors occurred in this letter by Douglas G Altman et al (7 November, p 1318). The last sentence should end "surely it makes sense also to report the relative risk when this differs markedly from the odds ratio" (not "surely it makes no sense ... ." as printed). Also, the first name of the second author is Jonathan, not Jonathon, and the second author of reference 2 is Bero LA, not Dero LA. 